\title{
Risk assesment in quality, environmental and safety operational control proceedings
}

\author{
Tatiana Karkoszka
}

\begin{abstract}
Realization of the operational aims of the organization, planned within the range of the integrated quality, environmental and occupational safety management system, very often remains unintegrated, which in turn creates the necessity for searching the new solutions ensuring the real integration, which has been confirmed by the literature review and the initial analyses. The originality of the study is due to the authorial method of the integrated assessment of the process, which enables pointing its key operational criteria by valuing the difficulty of realization as well as valuing the integrated risk for each of the operational criterion. The developed methodology has been applied in the organization being in possession of the implemented integrated management system, however, describing the operational level of this system as the unintegrated one. The effect of implementing the methodology of operational processes criteria assessment, pointing the key criteria and their operational monitoring, was, confirmed by the organization, improvement of the actions effectiveness within the range of integration in planning and realizing the aims. Findings of the research are as follows: the developed methodology of the operational criteria assessment can constitute the complex tool for assessment of the realized by the organization processes in the context of possibilities for integrated fulfillment by these processes the following requirements: quality, environmental and occupational safety, and simultaneously giving the guidance for improving them. The methodology can also be the integral part of the operational control model being the base for ensuring the supervising conditions in the organizations which in the future will be willing to adjust their processes to the Operational planning and control requirements of the following amended norms: ISO 9001, ISO 14001 as well as ISO 45001.
\end{abstract}

Keywords-operational control, quality, environment, occupational safety, integrated management systems, risk

\section{Introduction}

The basic element of the integrated quality, environmental and occupational safety management system, which should undergo the integration process, are the aims $[1,2]$. However, the experience of the organizations point that the integration of the normalized requirements of the management systems, in reality, is limited to the general systemic solutions [3-5].

Study on the integration level of the management systems, being in accordance with the following norms: ISO 9001, ISO 14001 and OHSAS 18001 [6-8], confirm that the scope of Product realization for $30 \%$ of the examined organizations is only partially integrated and for even $9 \%$ of the examined organizations is not integrated at all $[3,9]$.

Tatiana Karkoszka

Silesian University of Technology

Poland
Therefore, the organizations are searching for various ways which would enable them simultaneous effective realization of the integrated aims and on the operational level. These activities are of various character, including also introducing and implementing the integrated management system based on the authorial models [9-12].

The problems connected with lack of full integration of the management systems are faced by International Organization for Standardization, which is preparing the novelization of the so-far effective norms. As agreed, the unification of the requirements of new norms: ISO 9001, ISO 14001 and ISO 45001, should ensure the compatibility between the requirements of the particular standards - by implementing the approach based on the risk and the same structure. Special importance, due to the management on the operational level, has the point Operational planning and control [13-15].

It requires from the organization application of such solutions which will enable the compliance of the realized processes with the specific criteria of these processes. In practice, they may constitute the basis for realization of the processes, which will enable the minimizing of the risk connected with occurrence of the nonconformities, environmental impacts and the results of the workplace safety threats [13-15]. Here, appears also the necessity of modeling the solutions aimed at the integrated operational actions.

The answer to the above presented is the authorial model of operational control, aiming at ensuring the compliance between the planned criteria of the process and its real parameters. It's crucial element is the integrated assessment of the operational processes criteria and pointing the keycriteria which should undergo the operational monitoring. For the organization, it means application of the processes assessment allowing for taking into consideration not only the quality of the products and the sustainable development but also the other criteria $[16,17]$.

Numerous methods, being applied nowadays, in the assessment of the technological processes are of the quantity and quality character $[18,19]$. The methods which are rarely applied, apart from the wide possibilities of application within the range of: definition of issues, impact identification, effected environment description, impact prediction and impact assessment, are the methods based on the risk assessment [20,21].

The risk assessment, in the direct understanding, means identification of the risk together with taking into account its sources, analysis of the risk resulting in appointing its level and assessment of the acceptability by comparing the results of the assessment to the approved criteria of acceptability [22].

Such defined risk assessment can be used in the quality, environmental and occupational safety risk assessment on the level of the integrated assessment of the processes' 
influences. Therefore, it may constitute the starting point for the identification of the unacceptable risk and for taking up the operational actions minimizing the risk in question [23-25].

In such a context the subject of the work is the methodology of the process risk assessment, being the part of the operational control model enabling the realization of the integrated aims of the organization.

\section{Risk methodology in operational control}

The aim of the study was development of the methodology concerning the integrated assessment of the operational criteria of the process allowing for pointing the key criteria. The methodology in question represents the integral and fundamental element of the integrated operational control model and is based on the risk assessment connected with occurring the threats in the processes - Fig. 1 .

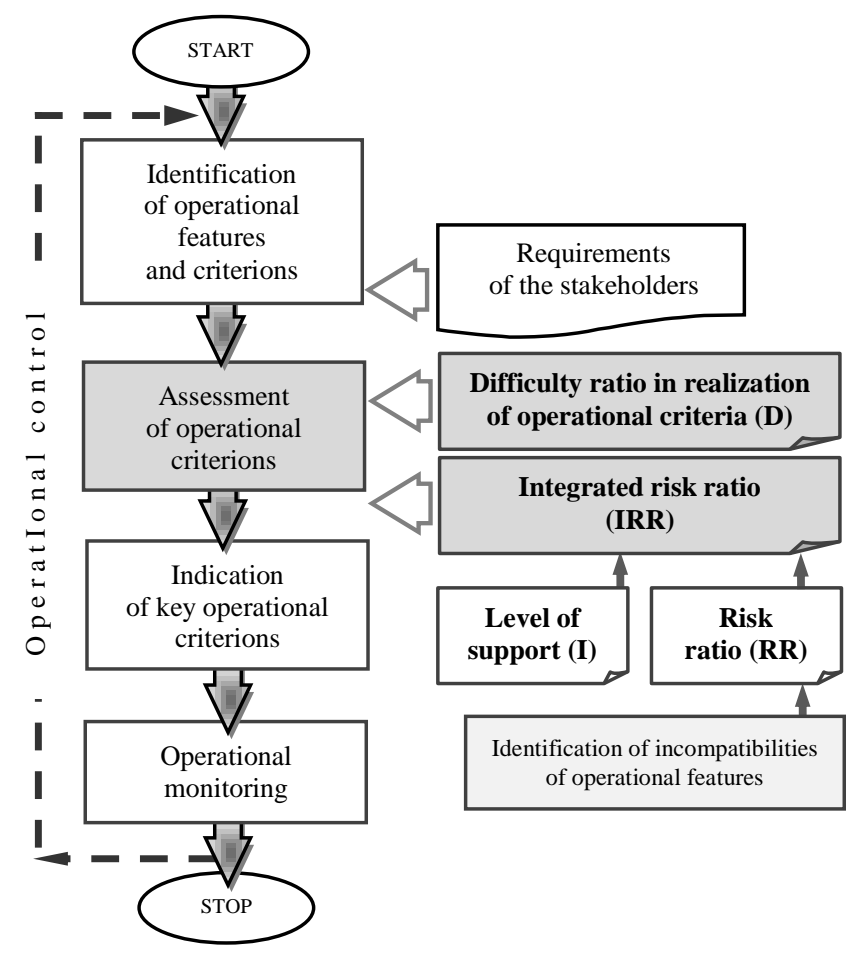

Figure 1. Scheme of the operational control in consideration of the assessment of operational criterions.

The developed model is the response to the results of the literature analyses and the initial study in the range of necessity of searching the solutions enabling integration of the operational actions undertaken by the organizations being in possession of the implemented management systems.

\section{A. Results of the initial study}

The carried out initial study, with the usage of polling survey, allowed for identification of these requirements of quality, environmental and workplace safety management systems, which creates within the organization the highest problems in integration.
Almost $60 \%$ of the survey's participants pointed at the operational level of the activity as unintegrated one. To the following question: "Does the operational control cover inclusively aspects of quality, environment and workplace safety" $9,1 \%$ of the respondents answered "yes", $31,8 \%$ answered "rather yes", 47\% answered "rather not", 11,4\% answered "not". Simultaneously, as many as $37 \%$ of the questioned organizations characterized the Measurements and the assessments of the processes as unintegrated ones.

The results of the initial study were identical with the results of the survey concerning the integration level within various scopes of the integrated management system, which were described in literature [3].

Therefore, it gives the basis for the statement that the problematic case in the organizations is the lack of integration within the range of method of processes estimation and as a result - lack of possibility for integrated control, which in turn creates the need for improvement in this range.

\section{B. Operational control}

The operational control is a way of the operational risk management by the realization of the processes in the supervised conditions due to ensuring the compatibility of the key criteria and the operational features with the legal requirements, technical specifications and other requirements stated by the all interested parties. Application of the operational control makes possible stable realization of the processes, also the technological ones, from the point of view of obtaining the agreed parameters of the manufactured goods as well as the influence of the monitored processes on the environment and the workers. Its effectiveness has been verified in the organizations being in possession of the implemented integrated management system [12].

The developed control model covers the following:

- identification of the operational features and operational criteria of the process,

- assessment of the features and operational criteria based on the methodology of the risk assessment in the process,

- appointing the features and criteria of the key character,

- control with the key operational criteria,

- operational monitoring taking into consideration the assessment of the integrated stability and ability of the process as well as the statistical control with the key operational criteria.

As the operational criteria, one has defined, within the scope of the described model, the technological parameters of the process, and the operational features have been defined the parameters determined by the legal requirements, technical specifications and other requirements stated by the interested parties. As the key operational criteria, one has pointed these ones which, due to the high accompanied risk, must undergo the operational supervision. 


\section{Methodology of the processes assessment}

The developed methodology of the process risk assessment (Fig. 1) represents the starting point for the operational monitoring. It covers the definition of the operational criteria realization difficulties (D) and the determination of the integrated risk ratio of each of the operational criterion (IRR) based on the risk ratio of the particular incompatibilities of the operational features (RR) and the force of influence of each criterion on the realization of these features (I).

Determination of the RR value is preluded by the identification of the potential threats and incompatibilities. The last ones have been defined as nonconformities (each was labeled with the QRR value), environmental impacts (each was labeled with the ERR value) and effects of the occupational safety threats. The identification process takes into consideration the following information concerning:

- application of the technology, including the using the machines and devices together with the safety instructions approved by the manufacturers,

- instructions of the processes,

- legal regulations and the requirements of the norms applied for the particular process,

- results of the measurement of work environment parameters concerning the scope of physical, chemical, biological and mechanical factors being harmful, troublesome and dangerous,

- results of the measurements of affecting the environment within the following scope: introducing the gases or dust into the air, producing and recycling of the waste, noise emission and electromagnetic fields,

- results of the check-ups and observations of the realized processes.

The base of the assessment of each incompatibility is application of the risk ratio (RR) being the product of priority number of importance, priority number of occurrence and priority number of supervision, and it covers the following:

- $\quad$ significance of the nonconformities, environmental impacts as well as the results of the occupational safety threats; importance of each of the incompatibility is reflected by the priority number of importance, which takes the value PRS $=1 \div 10$,

- probability of nonconformities, environmental impacts as well as the results of the occupational safety threats; occurrence probability of each of the incompatibility is reflected by the priority number of probability, which takes the value PRO $=1 \div 10$,

- effectiveness of supervising the process in the context of the applied methods of controlling the threats of quality, environment and safety as well as their results; the possibilities of supervision are described by the value $\mathrm{PRC}=1 \div 10$.
The value of RR is the product of the following priority numbers: importance, occurrence and supervision for each of the incompatibility (1):

$$
\mathrm{RR}=\mathrm{PRS} \cdot \mathrm{PRO} \cdot \mathrm{PRC}
$$

The value assigned to the priority numbers depends on the developed guidance being the description of the particular situations and integrated part of the model.

The difficulty of fulfilling the requirements connected with the operational criteria is defined and assigned by the ratio of difficulty of realizing the operational criteria (D). It has the expert character and takes the value from 1 to 5 . Realization of the technological parameter of highest value of the ratio can accompany the highest number of the difficulties, and the parameter in question requires the special attention during the realization of the process. The ratio of performance difficulty confirms the problem-free realization in the range of the existing technicalorganizational conditions.

The influence of the realization the operational criterion on the ensuring the operational features, is defined as the level of support (I). The force of this influence is characterized as the weak, middle or strong one and is ascribed by the following values: 1,3 and 9. Defining the dependence between the features of quality, environment and the workplace safety and operational criterions shows in which way the realization of the particular criterion influences on obtaining the highest amount of the optimal features.

The value of the integrated risk ratio (IRR) for each of the operational criterion represents the sum of the products of the risk values for the particular operational features (RR) and their level of support (I) with the particular operational criterion.

The key operational criteria, undergoing the monitoring process, are the criteria described with the high values of the integrated risk ratio as well as the ratio of realization difficulty.

\section{Risk proceedings in the chosen processes}

The developed methodology of risk assessment has been applied in the assessment of the chemical treatment process of steel elements. The process in question covered the following operations: sulfuric acid etching, rinsing, borax covering in the sodium tetraborate decahydrate solution and sodium hydroxide solution and finally the drying process. Following the prepared methodology, in the first step, in the process there were identified nine potential incompatibilities among which the following were described by the highest QRR values: hydrogen steel degradation, residue of the rust on the surface as well as the breach of the material structure. In the range of affecting the environment, among eleven identified environmental threats of special importance were the threats described by high ERR values: emission of particulate matter, sulphur dioxide, nitrogen dioxide, carbon monoxide, appearance of the wastewater of the physicchemical character posing the threat especially for the waters and soil, and first of all the risk of the industrial accident refraining from the application of the acids' solutions. 
The threats of the work safety, however, refrained from the contact with the hot surfaces and with the sulfuric acid and its fumes, possibility of slip and fall as well as the overload of the musculoskeletal system and stress.

Next, one has calculated the values related of the risk ratio in the range of quality, environment and safety - Table 1.

Table 1. Comparison of the exemplary threats and assigned them values of the following priority number: significance, occurrence and supervision as well as the risk ratios (RR).

\begin{tabular}{|l|c|c|}
\hline \multirow{2}{*}{$\begin{array}{c}\text { Quality, environmental } \\
\text { and occupational threats }\end{array}$} & $\begin{array}{c}\text { Rriority ratios } \\
\text { PRS, } P R O, P R C\end{array}$ & $\begin{array}{c}\text { Risk ratio } \\
\text { QRR/ERR/ORR }\end{array}$ \\
\cline { 2 - 3 } $\begin{array}{l}\text { Impairment of the material } \\
\text { structure }\end{array}$ & $7,8,2$ & $\mathrm{QRR}=112$ \\
\hline Hydrogen steel degradation & $10,8,8$ & $\mathrm{QRR}=640$ \\
\hline After-etching wastewaters & $9,10,1$ & $\mathrm{ERR}=90$ \\
\hline Emissions into the air & $3,10,2$ & $\mathrm{ERR}=60$ \\
\hline Contact with the hot items & $6,7,7$ & $\mathrm{ORR}=294$ \\
\hline Skin contact with the acids & $5,6,6$ & $\mathrm{ORR}=180$ \\
\hline
\end{tabular}

Next, one has calculated the value of integrated risk ratio (IRR) for each of the operational criterion. The way of dealing with the chosen operational features has been presented in the Table 2 .

Table 2. Matrix of the exemplary values of the risk ratio (RR) and level of support (I).

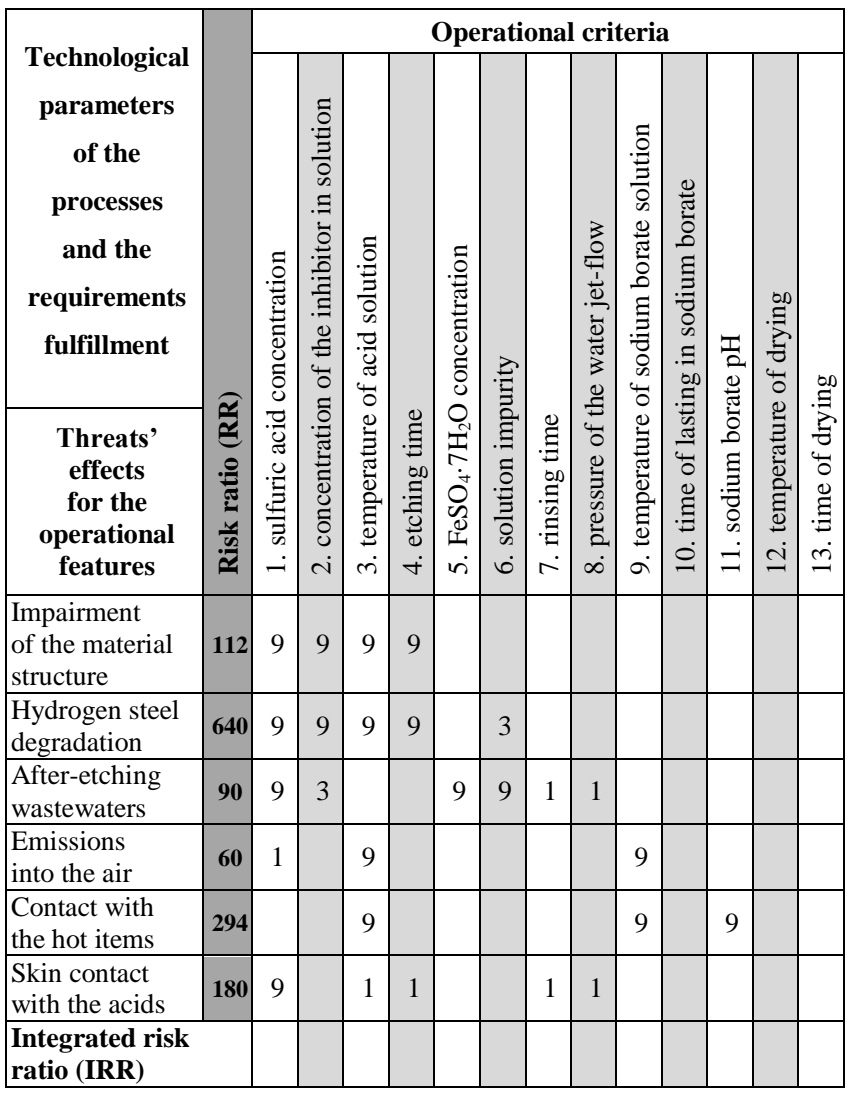

As a next step, one has appointed the values of the operational criteria realization difficulty ratio (D), which together with the values of integrated risk ratio (IRR) and finally compared in the table 3 , at the same time presenting the key criteria.

Table 3. Comparison of D and IRR values for the analyzed process together with the presentation of the key criteria.

\begin{tabular}{|l|c|c|}
\hline \multicolumn{1}{|c|}{ Operational criteria } & $\begin{array}{c}\text { Integrated risk } \\
\text { ratio (IRR) }\end{array}$ & $\begin{array}{c}\text { Difficulty ratio } \\
\text { (D) }\end{array}$ \\
\hline Sulfuric acid concentration & 19291 & 1 \\
\hline $\begin{array}{l}\text { Concentration of the inhibitor } \\
\text { in solution }\end{array}$ & 12031 & 1 \\
\hline Temperature of acid solution & 19905 & 1 \\
\hline Etching time & 9081 & 5 \\
\hline FeSO ${ }_{4} \cdot 7 \mathrm{H}_{2} \mathrm{O}$ concentration & 4155 & 1 \\
\hline Solution impurity & 4275 & 1 \\
\hline Rinsing time & 2349 & 1 \\
\hline Pressure of the water jet-flow & 2797 & 1 \\
\hline $\begin{array}{l}\text { Temperature of sodium borate } \\
\text { solution }\end{array}$ & 6755 & 1 \\
\hline Time of lasting in sodium borate & 1159 & 1 \\
\hline Sodium borate pH & 5512 & 1 \\
\hline Temperature of drying & 1270 & 1090 \\
\hline Time of drying & & 5 \\
\hline
\end{tabular}

\section{Conclusions}

The requirements within the range of operational control, covered by the following new norms ISO 9001, ISO 14001 and ISO 45001, point at the necessity of implementing such solutions which will prevent from the departure from the aims concerning: quality, environment and the workplace safety. The real differentiation of these aims in the organizations, however, makes difficult the unification of the undertaken actions on the operational level. Therefore, it is necessary to search for such solutions which would allow for the realization of the operational control in an integrated way.

The answer to such needs is the authorial model of the integrated operational control based on the identification and the assessment of features and operational criteria, appointing the key criteria and monitoring them. Its fundamental part is, constituting the issue of the study presented, the original methodology of assessing the operational criteria. It is based on the expert analysis of the process, taking into consideration not only the difficulties of realization the operational criteria but also the integrated risk of each operational criterion refraining from the risk of particular incompatibilities as well as the force of influence of each criterion on the realization of operational features.

The carried out in such a way the integrated risk assessment can represent the complex tool for assessment, analysis and improvement of the processes in the aspect of ensuring quality, minimizing the negative influence on the environment and limiting the safety threats.

The effectiveness of the integrated operational control model, together with the described methodology of the processes assessment, has been confirmed in the really functioning organization.

Application of the developed methodology in the analyzed process allowed for appointing the operational criteria which were difficult in realization as well as burdened with high risk of the incompatibility occurrence. 
In the context of realization difficulty the following key criteria were found: concentration of inhibitor $(D=5)$ and concentration of $\mathrm{FeSO}_{4} \cdot 7 \mathrm{H}_{2} \mathrm{O}(\mathrm{D}=5)$ in the solution of sulfuric acid. Due to the high values of the integrated risk ratio as the key criteria one has pointed the following ones: concentration of sulfuric acid in the solution (IRR = 19291), temperature of the sulfuric acid solution $($ IRR $=19905)$ as well as concentration of the inhibitor in the solution $($ IRR $=12031)$ and etching time $($ IRR $=9081)$. These criteria were taken into account on the next stage of the operational control, namely, in the operational monitoring ensuring the compliance of the operational features and criteria with the requirements.

The analysis of the process with the application of the described method has also confirmed that - due to the high cumulative integrated risk of all the operational criteria - it constitutes special threat in all of the integrated range.

\section{References}

[1] S. Karapetrovic, "Musings on integrated management systems", Measuring Business Excellence, vol. 7 (1), pp. 4-13, 2003.

[2] S. Karapetrovic, and J. Jonker, "Integration of standardized management systems: searching for a recipe and ingredients", Total Quality Management, vol. 14 (4), pp. 451-459, 2003.

[3] M. Bernardo, M. Casadesus, S. Karapetrovic, and I. Heras, "How integrated are environmental, quality and other standardized management systems? An empirical study", Journal of Cleaner Production, vol. 17 (8), pp. 742-750, 2009.

[4] A. Douglas, and D. Glen, "Integrated management systems in small and medium Enterprises", Total Quality Management, vol. 11 (4-6), pp. 686-690, 2000.

[5] S. Karapetrovic, M. Casadesus, and I. Heras, "Dynamics and integration of standardized management systems: an empirical study", Girona, Spain: Documenta Universitaria, 2006.

[6] ISO 9001, "Quality Management Systems - Requirements", International Organization for Standardization (ISO), Genève, Switzerland, 2008.

[7] ISO 14001, "Environmental Management Systems", International Organization for Standardization (ISO), Genève, Switzerland, 2004.

[8] OHSAS 18001, "Occupational Health and Safety Management Systems -Requirements", British Standards Institution (BSI), London, UK, 2007.

[9] M. Bernardo, "Integration of management systems as an innovation: a proposal for a new model", Journal of Cleaner Production, vol. 82 (1), pp. 132-142, 2014.

[10] T. H.Jørgensen, A. Remmen, and M. D. Mellado, "Integrated management systems - three different levels of integration", Journal of Cleaner Production, vol. 14 (8), pp. 713-722, 2006.

[11] S. X. Zeng, J. J. Shi, and G. X. Lou, "A synergetic model for implementing an integrated management system: an empirical study in China", Journal of Cleaner Production, vol. 15 (18), pp. 1760-1767, 2007.

[12] T. Karkoszka, Risk in fulfilling the quality, environmental and occupational safety requirements, Katowice: Śląsk, pp. 1-282, 2013.

[13] ISO/TC 176/SC 2/N 1147, ISO/CD 9001, "Quality management systems - Requirements", 03.06.2013.

[14] ISO/TC 207SC 1N 1067, ISO/CD 14001, "Environmental management systems - Requirements with guidance for use", 07.03.2013

[15] ISO/PC 283, ISO/CD 45001, "Occupational health and safety management systems - Requirements", 07.07.2014.

[16] A. L. Porter, "Technology assessment", Impact Assessment, vol. 13, pp. 135-151, 1995.

[17] A. Rip, and J. Schot, "The past and future of constructive technology assessment", Techological Forecasting and Social Change, vol. 54, pp. 251-268, 1996.
[18] K. E. Lemons, and A. L. Porter, "A comparative study of impact assessment methods in developed and developing countries", Impact Assessment Bulletin, vol. 10, pp. 57-65, 1992.

[19] Y. Bakouros, "Technology evaluation. Report produced for the EC funded project INNOREGIO: dissemination of innovation and knowledge management techniques", University of Thessaly, 2000.

[20] L. W. Canter, and L. Canter, Environmental Impact Assessment, 2nd ed., New York: McGraw Hill Publishing Company, 1996.

[21] L. W. Canter, "Pragmatic Suggestions for Incorporating Risk Assessment in EIA", The Environmental Professional, vol. 15 (1), pp. 125-138, 1993.

[22] ISO 31000, "Risk Management - Principles and guidelines", International Organization for Standardization (ISO), Genève, Switzerland, 2009.

[23] M. Roszak, M. Spilka, and A. Kania, "Environmental failure mode and effects analysis (FMEA) - a new approach to methodology", Metallurgy, vol. 54, pp. 449-451, 2014.

[24] T. Karkoszka, and M. Soković, "Integrated risk estimation of metal insert gas (MIG) and metal active gas (MAG) welding processes", Metallurgy, vol. 51, pp. 179-182, 2012.

[25] T. Karkoszka, and M. Soković, "Risk based on quality, environmental and occupational safety in heat treatment processes", Metallurgy, vol. 53 , pp. 545-548, 2014.

About Author:

Tatiana Karkoszka is an Assistant Professor in Institute of Engineering Materials and Biomaterials of Silesian University of Technology in Gliwice.

Her scientific interests' center is processes management in the aspect of quality, environmental and occupational safety as well as integrated methods of processes' analysis and risk assessment. 